At various epochs in the history of Medicine, it has been hoped that it might become a special branch of chemical science. Some years ago this hope assumed a more definite and apparently promising form than it had ever before done. How we have been disappointed in this direction it is needless to show. No one now contemplates the possibility-save in some few exceptional instances-of forming out of two active disturbing causes, disease and chemical remedy, the neutral compound, health. Because there is a prevalence of acidity superficially apparent, we do not therefore calculate that alkalies will cure the pathological condition in which it is manifested, nor vice versâ. We cannot with certainty calculate even upon altering an acid or an alkaline condition of the secretions by the obvious chemical resources. On the contrary, there is no more certain mode of relief known, for some conditions of the stomach in which intense acidity is a prominent symptom, than the administration of acids.

Science is knowledge, but such knowledge is not power in any practical sense. We know the motions of the planets, and can predict their phenomena with the utmost exactness, but we cannot influence them in any way. By science we know disease: science is diagnostic.' It is by art that we treat it: art is therapeutic. All our art is derived from experience. It may be that in some few instances à priori considerations lead us to try certain modes of treatment; but in general they are empirical, and in all cases the final acceptance or rejection of the method is governed by experience. This could not be were Medicine a science. Science knows, and is precise and positive. Art is variable, and selects. Science submits to no ignorance ; but art is ignorant of much. Science is essentially contemplative; art is active. In the apt antithesis of Dr. John Brown: Science puffeth up; art buildeth up.

Practically, the result of this error of theory is this : with every advance of science, we are too much disposed to think that an alteration in our art is necessary; otherwise we should be tacitly admitting the barrenness of the science. We forget the results of long experience, to run after the phantoms eroked by our improved knowledge. We make a discovery in chemistry or in microscopical science, and we are but ill satisfied if we cannot adapt it to our art. We improve in physiological knowledge; we learn the functions of a nervous tract with greater certainty; or we trace the relations of certain organs to extraneous influence more accurately; and in accordance with this, we alter modes of treatment which, up to the present time, we have been accustomed to think and to find satisfactory. Our disappointment in the result does not always teach us wisdom for the future.

I do not propose to enter deeply into the abstract question, but will merely state what I believe to be the fact, that pure science has in general done but little for art; whilst art has constantly and largely been contributing to the progress of science. In our profession this has eminently been the case : not the men of science, but those of careful and accurate observation, have generally been the men distinguished for healing gifts. Avoiding any allusions to men of the present day, let me illustrate my meaning by contrasting Harvey, the man of science, with Sydenham, the man of concrete observation; Sir Charles Bell, the discoverer, with Abercrombie, the physician.

Medicine has the same relation to science that poetry or painting has; and inasmuch as the most complete knowledge of the laws of perspective and the theory of light and colours would fail to make a painter; or the most intimate acquaintance with the rules of versification would fail to make a poet; so the profoundest knowledge of physiology and of all the sciences tributary to Medicine would entirely fail to make a competent physician. Medicine is a faculty to be acquired, not a lesson to be learned-to be acquired by long and patient observation of complex phenomena, in their ever-varying combinations,--not to be reduced to the hard and inelastic formula of science. In itself, I reverence science; but, in the interests of true progress and of humanity, I trust we shall, for the future, hear more of the art of healing and less of the science of Medicine.

2. The most important consequence of this theoretical error is, the false system of education that is entailed and necessitated thereby. Medicine being considered a science, it appear's necessary to cultivate all the collateral sciences to the utmost. A man may be legally qualified to practise medicine at twenty-one years of age. By that time he must have an accurate and minute knowledge of descriptive and general Anatomy; he must be well versed in the latest views on Physiology; his knowledge of Pathology must be well vouched for; he must be sufficiently versed in Chemistry to be enabled to analyse ordinary solutions, besides cumbering his memory with names, numbers, and proportions without limit; he must be able to describe in scientific phrase any plant which enters into the composition of the Materia Medica, and to anatomise any leaf or flower secundum artem; and he must have a competent theoretical knowledge of the principles and practice of Medicine and Surgery. By this time, also, he will have seen much operative surgery, and a minimum of medical practice at the hospital; and he must have practised vaccination, obstetrics, and the minor operations of surgery; eking out this trifling curriculum with the study of Forensic Medicine and Toxicology. Should he be destined for the higher walks of the profession, it would be much easier and shorter to enumerate the few subjects he need not study, than to catalogue the heterogeneous farrago of learning with which he must bewilder his unfortunate brain. It is evident that much of this learning must be acquired in a superficial and perfunctory manner, and that the knowledge necessary for passing the examinations must be "crammed"-to be disgorged and forgotten at the earliest possible period afterwards.

(To be concluded.)

ON THE

\section{ARSENICAL TREATMENT OF PHTHISIS}

BY T. F. SANGER, M.R.C.S., SURGEON TO THE COMTALESCENT HOSPITAL, SEAFORD.

About a year ago I had a case of phthisis under my care. The patient was a man aged twenty-eight, in whom the disease was hereditary, and two of his brothers had died of it. $\mathrm{He}$ was then taking citrate of iron and quinine, with iodide of potassium and cod-liver oil, from which he seemed to derive little benefit. Some spots of eczema appearing on the neck and chest, I substituted five minims of the liquor arsenicalis for the iodide of potassium in the iron mixture, and after he had taken it two or three weeks I was very much pleased to find that, although the eczema was not cured, his chest symptoms were much relieved, as he breathed more freely, his cough was less troublesome, he had gained strength, and increased in weight. Instead of succumbing to the disease as his brothers had done, he gradually improved, and when the cold weather set in he procured admission to a consumption hospital, where he remained two months. He came out in March, rather weaker than when he went in. I put him again upon the arsenical treatment, and it has brought him back to about the same state of health he was in when he left for the consumption hospital.

In The LanceT of November 21st, 1868, there is an article on the administration of arsenic in consumption, which contains an abstract of the reports of MM. Hérard and Moutard-Martin on the therapeutical use of that drug: I therefore determined on giving it a further trial.

A large percentage of the patients sent to the Convalescent Hospital are cases of incipient phthisis, and a few (although it is contrary to the rules of the institution) are patients in whom the disease is more advanced. These, in addition to my own private and parish patients, afforded me a good opportunity of testing the value of arsenic in arresting the progress of the malady. I cannot give the details of every case treated by the arsenic, but in almost every one the patients derived benefit from it; and several that I thought were hopeless improved beyond my most sanguine expectations.

I generally administer the arsenic in five-minim doses of the liquor arsenicalis, or solution of the arsenite of soda, twice a day, combined with a drachm of the citrate of iron wine, or five grains of the citrate of iron and quinine; and I am very particular in directing the medicine to be taken 
soon after a meal, and that it should be discontinued if any irritability of the stomach or bowels comes on during its administration. In some cases, especially where the patients are not able to tolerate any preparations of iron, I combine the arsenic with the hyposulphite of soda in doses of fifteen to twenty grains.

Martha S-, aged twenty-three; incipient phthisis, slight hacking cough, not much expectoration, dulness on percussion over the apices of both lungs, very anæmic, skin and conjunctiva a dirty-yellow colour. Says "she has been ailing for two or three years; has taken a great deal of medicine, but cannot tolerate steel." She commenced taking five minims of solution of arsenite of soda, with fifteen grains of hyposulphite of soda, the first week in April ; took the medicine up to the 28th May, when she was discharged cured.

John $\mathrm{H}-$ - aged thirty-four, lived for some years in a malarious district, near a tidal river ; has suffered from dyspnoea, cough, and emaciation for two or three years, during which time he has been unable to do any kind of work, and has been for some months a patient in the Brighton Hospital. He commenced on the 20th January to take five minims of Fowler's solution, with one scruple of the hyposulphite of soda, twice a day. He continued to take it up to the 10th of April, when he was returned as cured. He resumed his employment as farm labourer, and has been at work up to this date.

The situation of the Convalescent Hospital at Seaford is very favourable for the treatment of the early stages of consumption, and it may therefore be said that the success of the treatment should be partly attributed to the healthiness of the place. Seaford is remarkably dry, the subsoil being chalk or porous sand; consequently, there is very little surface evaporation, and after the heaviest rains the roads are free from mud and dirt. The country rises gradually behind the town to the breezy Southdown hills, and is defended from the north and east winds by the Beachy Head range of cliffs, which rise to a height of between 600 and 700 feet. The drainage of the place is now as perfect as in any town in England, the sewage being discharged into the sea at a part remote from any dwelling, and in a way which prevents its interfering with the comfort of bathers.

The eity of Salisbury, when I lived there thirty years since, was called "the sink of Wiltshire, the close the sink of Salisbury, and the Bishop's palace the sink of the close." The death-rate was almost as high as in any city or town in England, ranging from 27 to 29 in 1000 . Good drainage and a pure water-supply have reduced the general mortality 40 to 50 per cent., and lessened the deaths from phthisis (according to the statistics of Dr. Buchanan and Mr. A. Middleton) 50 per cent. If good drainage, by lessening surface evaporation, and purifying the atmosphere, reduced the incidence of death from consumption just one half, in a city situated as Salisbury is, what is it likely to do for a town so healthily placed as Seaford, where the death-rate has been as low as 13 in 1000 at a time when the two healthiest districts in England (Helstone and Eastbourne) were 15 in 1000 .

Seaford, May $28 \mathrm{th}, 1869$.

\section{ON THE TREATMENT OF SCURVY BY THE BINOXALATE OF POTASH.}

COMMUNICATED BY

W. H. TAYLER, M.D.,

TROM OBSERVATIONS MADE IN THE ARCTIC REgIONS BY J. W. TAYLER, F.R.G.S., F.G.S.

IN 1854 and 1855, my brother, Mr. J. W. Tayler, was engaged at Evigtok, West Greenland, about lat. $61^{\circ} 20^{\prime}$, in working some lead mines, and had under his charge fourteen men. During that period all hands except himself and the steward were affected with scurvy. After exhausting his stock of lime-juice and citric acid, nsing up all his claret, jams, and everything that would be likely to be of service, he bethought himself of the fact that sailors, when suffering from the want of fresh meat and vegetables, take every opportunity, when they get on shore, of hunting for sorrel, and that those affected with scurvy rapidly improve under its use. As a chemist, Mr. Tayler considered what remedial agent the plant contained; and knowing binoxalate of potash to be present in it, he determined to try that salt. Having some oxalic acid and potash, he manufactured a compound of binoxalate of potash with an excess of oxalic acid, and commenced his treatment of the men laid up with scurvy. He gave four-grain doses three times a day. A rapid improvement followed: the men, though still living on the same diet, soon lost all symptoms of the scurvy; and all recovered except one man, who died after travelling seventy miles in an open boat, and when within sight of the vessel which was to take him home, he being unable to bear the exposure and fatigue of the journey. All the men were affected with scurvy in its most virulent form.

In 1865, Mr. J. W. Tayler went to Exeter Sound, and there landed his men and stores for the purpose of forming a settlement for whale fishing.

In 1866-67, though there was a fair supply of preserved meat and vegetables, lime-juice, pickles, \&c., several of these men became affected with scurvy, and two died; but the binoxalate of potash treatment was not adopted, the medical man then in temporary charge preferring the usual remedies.

In 1867-68, many of the men were suffering from scurvy, and after trying lime-juice and other remedies without much improvement, the binoxalate of potash was given; the scurvy was soon checked, and all the men recovered. Occasionally the salt was discontinued, and the men at once retrograded; and they had such implicit faith in its prophylactic properties, that on the least symptoms of scurvy showing themselves, they came and asked for a powder of the binoxalate, which they took in the form of lemonade.

From the above facts, we appear to have in the treatment of scurvy a most valuable agent in the binoxalate of potash with oxalic acid. It is easy to obtain, can always be made of a uniform strength, its purity can be depended upon, it does not deteriorate by keeping, and is very inexpensive. It is also contained in the juices of many plants, particularly in the expressed liquor of the rhubarb-leaf, which, made into a syrup or extract, would probably answer well. Should a more extended trial by others prove it to be as successful a remedy as it was in the hands of Mr. J. W. Tayler, the boon to sailors would be great. In the navy and mercantile marine, it would not only save many valuable lives, but thousands of pounds, now almost uselessly expended in badly preserved meats and vegatables and adulterated limejuice. Mr. Tayler found that no consumable amount of preserved meat was equal to fresh meat as a health-sustaining diet, and the men were so eager for fresh meat that they often preferred bear to the preserved meats supplied in tins.

I will conclude my remarks by giving some of the symptoms noticed by Mr. J. W. Tayler in the men affected with scurvy. The men complained of languor and restlessness, were melancholy and low-spirited, and their appetite was capricious; they had aching pains down the front part of the legs, particularly on retiring to rest; small petechial spots appeared on the inner and lower third of the legs, spreading more or less rapidly, and forming large patches the colour of port wine; there was also tenderness of the teeth and gums. As the disease progressed, the breath became foul; spongy, fungoid, bleeding excrescences appeared about the gums and palate; there was great tenderness of teeth, and inability to eat hard food, such as biscuit; the teeth became loose and fell out; general codema existed; they were unable to walk without support; softening of the finger-nails took place, they becoming quite pliable; there was very great unwillingness to move about or assist themselves in any way, and they got discontented and very desponding; great debility came on, the body rapidly emaciated, giving off a most foul stench, and pediculi were frequently numerous. The patient may die on any sudden exertion, or gradually sink. In fatal cases, many go on for four or five months; but some slight cases recovered in a few days under the binoxalate of potash.

From the foregoing results I would draw the following conclusions :-

1st. That scurvy arises in a great measure from a deficiency of albumen in the blood.

2nd. That the diet of sailors and persons who stufer from 